NBER WORKING PAPER SERIES

POLICIES FOR A BETTER-FED WORLD

Abhijit Banerjee

Working Paper 21623

http://www.nber.org/papers/w21623

\author{
NATIONAL BUREAU OF ECONOMIC RESEARCH \\ 1050 Massachusetts Avenue \\ Cambridge, MA 02138 \\ October 2015
}

The views expressed herein are those of the author and do not necessarily reflect the views of the National Bureau of Economic Research.

NBER working papers are circulated for discussion and comment purposes. They have not been peerreviewed or been subject to the review by the NBER Board of Directors that accompanies official NBER publications.

(C) 2015 by Abhijit Banerjee. All rights reserved. Short sections of text, not to exceed two paragraphs, may be quoted without explicit permission provided that full credit, including $\odot$ notice, is given to the source. 
Policies for a Better-fed World

Abhijit Banerjee

NBER Working Paper No. 21623

October 2015

JEL No. I1,I15,I28,I38

\title{
ABSTRACT
}

A wide range of interventions, from subsidized grains all the way to conditions on nutrition in conditional cash transfers, have either been tried or put in place in different countries in order to fight under-nutrition. A number of important policy experiments in recent years, directly or indirectly, offer important insights into how best to design these interventions. This essay is an attempt to pull together some of those insights, with the aim of saying something about what the optimal design should look like.

\author{
Abhijit Banerjee \\ Department of Economics, E17-201A \\ MIT \\ 77 Massachusetts Avenue \\ Cambridge, MA 02139 \\ and NBER \\ banerjee@mit.edu
}




\section{Policies for a better-fed world}

\section{Abhijit V. Banerjee}

Policies aimed at reducing starvation and redressing nutritional deficiencies remain among the most widely accepted policies in the world. A wide range of interventions, from subsidized grains all the way to conditions on nutrition in conditional cash transfers have either been tried or put in place in different countries. In recent years there have been a number of important policy experiments that, directly or indirectly, offer important insights into how best to design these interventions. This essay is an attempt to pull together some of these insights with the aim of being able to say something about what the optimal design should look like.

As I see it, there are four central issues - how much, what form the transfer should take, what conditions should be attached to receiving it, and how it should be targeted. While, as we will see, there are many cross-cutting issues, it is still useful to tackle them one by one.

\section{How much?}

A part of how much of course has to do with how much the economy can afford and how much it is willing to transfer to the poor. But obviously there are efficiency issues as well; the returns to spending money on nutrition may be linear, convex (at least over a range), or concave, and that has important implications for program design.

A recent randomized control trial of an unconditional temporary cash transfer program operated by GiveDirectly in Kenya (Haushofer and Shapiro (2013)) offers some direct evidence relevant to these questions. In this experiment households were randomized to get either a transfer of either 25,200 Kenyan Shillings or 95,200 Kenyan Shillings. The elasticity of food expenditure with respect to total spending is substantially higher for the smaller transfer suggesting that there is indeed some concavity in food spending. This is consistent with the evidence on the shape of Engel curves estimated from cross-sectional data—Deaton and Subramanian (1996) do this for India, for example — and indeed makes intuitive sense.

There is also the important issue of the timing of transfers - should they be frequent and small, or occasional and larger? Some recent results suggesting that a one-time lump sum transfer might have substantial and long-term income enhancement effects. Blattman et al. (2014) report on a randomized evaluation of a program in Uganda's conflict-affected north where young men and women in the treatment group were invited to form groups and submit grant proposals for vocational training and starting business start-ups. Grants of $\$ 382$ per member were made, some of which gets invested in acquiring skills, and the rest on tools and materials. After four years, half of the program participants practiced a skilled trade, and business assets went up by $57 \%$, work hours by $17 \%$, and earnings by $38 \%$. Blattman et al. (2015) report on another program in Northern Uganda where randomly chosen extremely poor women where offered a package that includes $\$ 150$ in cash, five days of business skills training, and ongoing supervision. The evidence from the evaluation shows that 16 months after grants were given out, participants had doubled their microenterprise ownership and incomes. Banerjee et al. (2015) report on a set of six more or less simultaneous randomized trials in six different countries (Ethiopia, Ghana, Honduras, India, Pakistan and Peru) of the so-called graduation program that offers extremely 
poor women (the gift of) an asset combined with some training and some supervision. The average cost of the program was close to the yearly consumption in the baseline. The program lead to a sustained increase (meaning it was still going at least 3 years after the assets were given out) in consumption of about $5 \%$ when we average across the countries but larger effects in the poorer countries like India and Ethiopia. Moreover, at least in the poorer countries the internal rates of return on the program spending was 23\% in India, 13\% in Ethiopia and $10 \%$ in Pakistan, which are all relatively attractive. The original of this set of programs is the version implemented by BRAC in Bangladesh, which was also subject to randomized controlled trial (RCT), and generated results similar to that in our Indian sample. ${ }^{1}$ Finally, Bryan et al. (2014) report on a program in Bangladesh where, during the so-called hungry season (monga), potential migrants were offered a one-time gift of around $\$ 8.50$ if they migrated to one of the big cities to find a job. The amount was chosen to more or less cover the cost of the trip itself. It led to a substantial increase in seasonal migration and a 30-35\% increase in household consumption during the monga period. Moreover, about half the effect on migration persists in subsequent years.

Of these studies, Blattman et al. (2014) does not report the impact on food consumption, but Blattman et al. (2014) reports an increase of a third to a half in the total number of meals per day and correspondingly large reduction in going hungry. The studies of the graduation program explicitly focus on food spending and find a large impact on it, with the implied elasticity quite a bit greater than 1 . The migration study finds an increase of nearly 700 calories per day from near starvation levels.

Unfortunately, none of these studies tell us what would have happened if instead of the lump sum, they were given a monthly or weekly transfer. The exception is the Haushofer and Shapiro study, which also compares what happens if households get the same total amount of money as a lump sum versus 9 monthly payments. The elasticity for food expenditures is 1.19 with the monthly payments, but with a lump sum it goes down to 0.69 and more of the money goes into durables such as a metal roof, which, the authors suggest, may be a good investment because people actually spend over a hundred dollars a year repairing their roofs, whereas a metal roof is almost infinitely durable. If that is the case then the metal roof might pay off in increased food consumption in the future when the money would have otherwise been spent repairing roofsthis will not show up in a survey of just a few months after the intervention. ${ }^{2}$

However, this experience does suggest that households that receive a lump sum and do not want to invest it in an income-earning asset may find it difficult to save the money and spend it gradually over time. This may limit their ability to turn that money into food consumption. On the other hand, the lump sum does give them a chance to durably raise their income, so a key question is whether a monthly cash transfer could have the same effect on earnings. The monthly transfers in the Haushofer and Shapiro experiment in Kenya did lead to some income growth, mostly through investment in livestock, but the effect is small, certainly not large enough to undo the decline in consumption that we observe among the program beneficiaries over the 4 month period after the disbursement of the first round of benefits.

\footnotetext{
${ }^{1}$ See Bandiera et al. (2013).

2 This argument assumes, plausibly, that the program participants are credit constrained.
} 
It is possible that the absence of a larger effect on income from a monthly income support reflects the requirement to make a lump sum investment to get the business really going. But it could also be a result of the fact that the GiveDirectly intervention, unlike all the others we discuss, deliberately stays away from encouraging the beneficiaries to focus on investments rather than consumption. If it is the latter, it is not possible to properly evaluate the comparison between monthly and lump sum transfers, without costing out such encouragement (the encouragement, broadly construed, involved in the graduation program, cost almost as much as the asset, but maybe much less would have sufficed, as Blattman et al. 2014 seem to argue).

There is in fact yet another possibility; the different programs also target differently. The graduation programs targeted the poorest of the poor, who were typically underemployed before the intervention. The two programs in Northern Uganda, one of which was a part of a demobilization effort after years of conflict, were also explicitly targeted towards creating employment in an area where very few jobs were available. The migration subsidy served a similar purpose, though the problem was more seasonal than endemic. By contrast, the GiveDirectly program was targeted towards poor people, but not a group that was especially likely to be underemployed. Perhaps they were already fully employed, which is why the effect on income generation was small.

If this is the case, while lump sum transfers may be very important for certain specific populations, a more regular transfer may be more effective in promoting better nutrition in the broader population. At the current state of our knowledge, this question is not possible to settle; but given the various concerns, especially about generalizability to the broader population, the rest of this piece will focus on relatively frequent and smaller transfers, which is also what most policy makers are thinking about.

\section{Does money promote better nutrition?}

The good news from all the studies already mentioned is that when poor people get cash transfers, consumption goes up more or less in proportion (or even faster than that). This is consistent with a number of other studies of conditional cash transfers in a range of countries, summarized in (Fiszbein and Schady (2009)). The review reports that food shares went up as a result of the transfer in five of the seven countries-Mexico, Ecuador, Brazil, Colombia and Nicaragua - and did not change in the two others - Cambodia and Honduras. This is striking because the usual presumption is that an increase in total consumption will lower food share. All of this raises the possibility that raising people's disposable income could be a powerful tool for promoting better nutrition.

I must admit that this represents a partial shift away from a more pessimistic view that we took in our 2011 book Poor Economics (Banerjee and Duflo (2011)). The big difference from the fact in that book is we used cross-sectional estimates of the Engel curve to infer the effect of income on food consumption; these elasticity's have typically been quite a bit lower than the one or more that a number of studies are now finding, more in the range of 0.5 to $0.8 .^{3}$ Moreover, estimates of

\footnotetext{
${ }^{3}$ See Behrman and Deolalikar (1988), Deaton and Subramanian (1996), and the excellent review article by Strauss and Thomas (1995).
} 
the food share, even among the poorest, are often below 0.6 , especially in countries where there are other things that the poor can afford to buy (Banerjee and Duflo (2007)).

In India, for example, the food-share has been falling sharply (Deaton and Dreze (2009)) at all levels of income; for the average Indian the food share went from around $65 \%$ to near $57 \%$ over the 1983 to 2004 period. All of this creates the impression that food is not a priority for the poor, and indeed in Poor Economics, we quote a poor rural Moroccan saying that "television is more important than food".

The recent evidence on the impact of experimentally induced variation in income, however, suggests one of two possibilities: One is that, to the contrary, food is indeed a priority for most households - it is more that there are other necessities such as cell-phones and private schooling, which seem to take precedence over everything but the calories required to survive. Therefore, even though the food share is relatively low, the elasticity is actually greater than 1 -once people have their necessities, they move relatively quickly to higher food spending. The other is the fact that these are results from social transfers, which is important - perhaps they are spent differently than other monies.

The first explanation essentially says that the cross-sectional estimates of the Engel curve are biased downwards; this could be the case if there is classical measurement error in per capita consumption, but on the other hand it is plausible that the measurement error is positively correlated with total consumption since the rich tend to waste food, which would go the other way. If there is also a causal effect of food consumption on productivity/income and therefore on total consumption which varies with the level of consumption, the bias in the estimated "causal" effect of total consumption on food consumption can go either way. To complicate matters even further, people vary in how much food consumption they need to be productive, which gives rise to additional sources of bias. Given all this, there is strong no prima facie reason for why the bias should be downwards, though there is nothing to rule it out either. Perhaps as reaction to this unsatisfactory state of affairs, the reaction of the literature (as exemplified, for example, by (Ravallion (2009) (Fiszbein and Schady (2009)) has been to therefore emphasize the second potential explanation listed above-namely that money from social transfers is spent differently. One possible reason for this is targeting of the transfer towards women. Schady and Rosero (2007, 2008), who emphasize this explanation in the context of the BDH program in Ecuador, also show that, consistent with this explanation, the food share goes up in families where there is a prime aged man and a prime aged woman, but not in households where there is a only a prime aged woman. This is also consistent with the finding in Duflo (2003) that pensions in South Africa have an effect on child height when given to the grandmother but not to the grandfather. However, the one really clean test of this theory is in the Haushofer and Shapiro study we discuss above, where they randomized the gender of the family member who is entitled to the transfer, and finds absolutely no effect of gender.

There are of course many other reasons why a social transfer may be treated differently, including the fact that the receipt of a social transfer might prime people to think about their obligations towards their family. Or it could be that the recognition of their citizenship symbolized by the transfer, makes people more optimistic and forward-looking and therefore more willing to invest in the health of their children (Banerjee and Mullainathan (2010)). While 
we wait to figure out the true reason, it is useful to emphasize the core result: it seems to be possible to have a substantial effect on food spending by giving families social transfers, perhaps targeted towards women.

The fact that people spend money on food does not, of course, mean that they use it all to promote nutrition. Indeed all the evidence points towards quality upgrading in the food people buy - they buy more meat and dairy products as well as more expensive cereals. Deaton and Subramanian (1996) estimate that about half the extra money gets spent on getting additional calories; the rest is spent on more expensive foods. The total nutritional value of the additional purchases is harder to assess because there is no agreement on the relative value of calories versus other nutrients. However, it is notable that in a period where calorie consumption has been falling in India (but the consumption of animal proteins and some other nutrients has been rising), malnutrition in children has also been falling. Now of course there are other potential explanations of this surprising trend-better sanitation, less onerous physical labor-but it is consistent with the view that calories are not the only source of better nutrition.

That said, there is one piece of evidence that is a bit sobering. Manley et al. (2012) reviews the evidence on the effect of CCTs on child health and find no systematic evidence of a positive impact. A few programs such as the Apni Beti Apna Dhan program in India seem to have large positive effects on anthropometric measures, but some like the Rural Maintenance Program in Bangladesh had large negative outcomes as well. They point out, however, that the negative results seem to be from programs that did not have child outcomes as part of the conditionality and if to leave such programs out the results are more favorable. It is also possible that some of the programs were too small to impact child anthropometrics, especially since the benefits had to be shared with the rest of the family - perhaps adults benefitted where children did not. Nevertheless, this remains something to watch for as more evidence accumulates.

\section{Cash versus food}

The above discussion raises an important alternative possibility: if food spending is what we care about, would it not be even better to make the social transfers directly in food? There are a number of programs that do this including India's Targeted Public Distribution Scheme (TPDS) and Indonesia's Rice subsidy (Raskin). However, there are a number of reasons why this idea is not as obvious as it might seem. First, an RCT in four countries (Ecuador, Niger, Uganda, Yemen) of cash (or food vouchers) versus food transfers finds that delivering food is physically more costly and raises the cost of the program by between 10 and almost $30 \%$ (Hoddinott et al. (2013)). Moreover, these might substantially understate the possibility of losses since the delivery in these pilot implementations was tightly controlled. In full-scale programs the experience of many countries is that it is easy to food to get "lost" in the process of being transferred - rats eat grains in storage, trucks get diverted, etc. India's planning commission estimates leakage to be about $36 \%$ of the grains and mis-targeting to be another $21 \%$ of (Fiszbein and Schady (2009)) In Raskin the fraction of subsidy that actually reaches the intended beneficiary is one-third of the promised amount.

Of course similar losses could also occur with cash but using cash should at the very least eliminate the transit losses ( $36 \%$ in India) since the cash could be sent directly to biometrically 
identified beneficiary bank accounts. Because it is going directly to the beneficiary it also reduces the possibility of hold up by some intermediary, such as the Raskin distributor in Indonesia and the TPDS shop owner in India. The one problem it does not solve is the problem of mistargeting; more on that later.

Basic economics also tells us that the cash and food transfer should have very similar effects unless the amount of the transfer is larger than what the family would have purchased at market prices. ${ }^{4}$ This is because the price of the marginal unit is not altered by the transfer program; both interventions therefore simply raise the income of the beneficiary and the effect on food consumption should be identical as long as the transferred amounts are the same. In fact, most transfer programs are nowhere near fully replacing food purchases from the market - the Hoddinott et al. paper checks this for their four programs and confirms the claim-so we should not expect any difference between cash and food as long as they are worth the same under the standard model.

Of course the standard model does not have to be true; consumers could mechanically consume what they get in food in addition to what they would buy otherwise, or they could read the food transfer of a signal of what the government wants them to do. This is what Hoddinott et al. test and by their base measure of nutritional quality (not just calories) they find that nutrition improves with cash in three out of the four countries but worsens in the fourth. It is perhaps no surprise that the fourth country is Niger, where there are large areas with no local source of food. This is consistent with Cunha et al. (2011), which is another study that compares the effects of cash and food transfer using the methodology of randomized control trials, this time in the context of Mexico's Programa de Apoyo Alimentario (PAL). They find that food transfers have small price effects, except in very remote areas where the food supply is presumably either monopolistically controlled or just very inelastic. Either way it tells us that in areas where there is robust local food supply, cash transfers may be less attractive, but that should not rule out using them in most places or combining them with a supply-side intervention in remote areas.

Another paper by Cunha (2011) about the same experiment finds overall no difference between the effects of food and cash transfers, confirming the conclusion of an earlier study by Skoufias, Unar, and Gonzalez-Cossio (2008) about the same program. He also pays close attention to consumption of certain commodities that the government included in the bundle they were giving out for the express purpose of improving nutrition. These are things that people do not usually buy (such as powdered milk) and therefore those amounts were all marginal. He finds that there are some effects on nutritional quality, but surprising little because the consumers were apparently cutting back in buying some products that had similar nutritional content.

This level of sophistication is impressive but perhaps slightly concerning since it limits the possibility of improving nutrition without changing preferences. On the other hand, almost all of the studies that ask this question consistently deliver one piece of good news - we do not find evidence that the cash transfers are more likely to be used for buying alcohol or intoxicants - not only are the effects not significant, they are actually small or even negative. Since the fear that the money would be spent on such "social bads" is one of the standard arguments for food against cash, the evidence is reassuring.

\footnotetext{
${ }^{4}$ This assumes that people cannot resale what they get from the program, which is not always true.
} 
Overall there seems to be strong evidence in favor of going the cash route - cash is easier to implement well and plausibly, may help limit leakages, and its impact on the desired outcomes seem no worse. There are of course risks - for one, there may be households where the money may get spent on alcohol or otherwise wasted. Putting the money into a woman's account wherever possible is now widely accepted as one part of the response to this issue, but perhaps in some situations it makes sense to substitute food vouchers for cash to limit the choices even though as long as the transfer is infra-marginal its not clear that this helps. Hoddinott et al. (2013), in the paper already mentioned, finds that on average food and vouchers have very similar effects. Of course food transfers also face the same limitations; it is not clear it is possible to stop someone who is hell-bent on wasting the money, other than by altering bargaining power in the family.

That said, it is possible that some families will benefit from being able to choose between cash and vouchers/food according to their circumstances. This is the approach that SEWA (SelfEmployed Women's Association) has taken in India in its two experimental (though not randomized) implementations of cash transfers as a replacement for food transfers in the states of Madhya Pradesh (MP) and Delhi in India. While the evaluations are based on strong assumptions on the comparability of the treatment and control groups (particularly in Delhi where the two groups are formed by self-selection), the overall is worth reporting. Cash transfers do not reduce food spending and seem to increase many other forms of spending including those on healthcare and education. Moreover they are popular; those who were exposed to cash transfers strongly prefer to hold on to them.

The downside with giving people a choice is that the infrastructure of food delivery is expensive and leaky. But perhaps if few enough people want it, the implementation can be much more local (buy as much as the program needs in the local market and less inefficient). In any case this remains an important possibility to explore further.

\section{Conditionality's and Targeting}

These are actually distinct issues but in practice they tend to be closely connected, In particular conditions for receiving transfers, if enforced, and perhaps even if not enforced, tend to exclude some people and therefore end up targeting.

The political economy of why cash transfers became conditional has been discussed much better elsewhere (Levy (2008)). They essentially offered a fig leaf to justify making substantial social transfers. Subsequently, however, they have been used to incentivize quite specific social goals, as in the case of India's Janani Suraksha Yojana, which tries to get women to have hospital births.

From the point of view of the question we are asking in this essay, conditions are only useful if they either promote better nutrition or generate better targeting. We already discussed the potential value of cloaking transfers in the garb of good intentions; most countries already do this in one form or another - and children's nutrition is often a part of the standard narrative that goes with transfers. Information about good nutrition or infotainment campaigns delivered to 
beneficiaries taking advantage of their beneficiary status (say when they pick up the cash) may also help. ${ }^{5}$ It is not, however, clear that there is much more that can be done along these lines. Rewarding improvements in weight or height or BMI seems to be fraught with difficulties, mostly because the connection between better nutrition and these measures is never deterministic; perhaps the best ideas along these lines is to provide some extra rewards to families for every child who completes high school, which encourages families to focus on making long term investments in their children. ${ }^{6}$ Rewarding better diets may be possible, but the best way to do it is probably to offer price subsidies, not monitor what people are buying.

What then remains is targeting. A vast majority of social programs intend to target the poor, though the definition of poverty varies across programs (and obviously also across countries). However, in practice, targeting is often very imperfect. The Indian Planning Commission's (Fiszbein and Schady (2009)) evaluation of the Targeted Public Distribution System estimates inclusion errors (fraction of households who are not poor who get benefits intended for the poor) to be more than $35 \%$ in 3 states out of the 16 biggest, and more than $15 \%$ in 8 and inclusion error (fraction of poor households who do not get benefits) to be more than $25 \%$ in 8 states (out of 16) and more than $45 \%$ in two. For Indonesia's Raskin program the probability that an eligible household would receive subsidized rice was only slightly higher than the corresponding likelihood for an ineligible household.

The problem, in part, is that targeting is inherently hard; poverty is usually measured in terms of per capita consumption, but the per capita consumption at any point of time may not be a reliable index of a family's wellbeing, partly because consumption goes up and down a lot over time (think celebrations) and in part of liquidity issues. As a result, there is a lot of unavoidable guesswork in establishing who is poor. To add to this, collecting consumption data is expensive and most developing countries do not have reliable income statistics for those who are not in the organized sector, which is most poor people. Therefore, most developing countries use one of three methods to target: proxy means tests (PMTs), community based targeting or self-targeting or combinations thereof.

The basic idea of the PMT is for the government to collect some easy to observe measures of the wealth of potential beneficiary households (identified somehow) (whether they have brick house, a car, etc.). Then they use a model that they have previously estimated on a representative sample dataset that has both these wealth measures and consumption, to predict the consumption of the household. This is how the Indonesian government, for example, targets most of its social programs.

PMTs have the advantage of being much easier to collect and potentially more stable than actual consumption, but not particularly reliable as a welfare measure because the prediction model is never very accurate, both because it ignores differences in tastes across households and because the underlying data quality is often poor, in part because those collecting data have strong

\footnotetext{
${ }^{5}$ Independent of the transfer it may also be worth figuring ways to get people to take certain micronutrients that are missing from their diets. Giving them away or selling them on the market, ideally in the form of things people like to eat (Vietnam uses iron fortified fish sauce as a part of their campaign against anemia).

6 The Apni Beti Apna Dhan program mentioned already is an example of this kind of intervention as is Field and Glennerster (2013) in Bangladesh.
} 
incentives to manipulate it. In a study of small cash transfer program in Indonesia, we found that the measured average targeting success rate of a PMT was around $50 \%$, meaning that only half of the population who were classified as either above or below the poverty line actually belonged to that category based on our measurement of their consumption (Alatas et al. (2012)). ${ }^{7}$

One alternative to a PMT is to ask the community (somehow defined) to make up a list of those who it believes to be poor. India's Below Poverty Line (BPL) population, used for the assignment of most social programs, is a combination of community selection and a PMT. Alatas et al. (2012) reports on an RCT which compares community targeting with a PMT and finds that they do essentially equally badly - the PMT, which as we say above, has a 50\% error rateactually does slightly better. However, a part of that difference is because of the norm we are using to judge the two methods, which is per capita consumption. The paper shows clear evidence that the community deliberately deviates from that norm, in pursuit of its own sense of who is poor. Moral judgments are part of that judgment - for example, the community disapproves of people who have the capacity to earn more but "choose" not to do so. As a result, the RCT also finds that community is much happier about the selection of beneficiaries when it does the choosing than otherwise - there are many fewer complaints, for example.

However, there is also evidence that the community does not make use of all the information it has. The same RCT also randomized the order in which the community ranked the households and we find that the people ranked early are much more likely to be ranked correctly than those who are ranked later. We suspect this reflects the community becoming tired of doing the ranking exercise. It is possible that a different way of organizing the ranking process would have had very different consequences, but this is one of the reasons community ranking does not do better than the PMT.

Another concern with community ranking is that there will be elite capture. The suspicion is that village elites will contrive to allocate the benefits to their own relatives. Alatas et al. (2013a) test this by randomly allocating two different rules for the community process. In the first, the whole community is invited to do the ranking; in the second, only the elite gets to do it. They find absolutely no difference in the outcome.

The program studied by Alatas et al. (2013a) was not very representative in that it was a one time give-away of a small amount of money (\$3 or so). However, a similar experiment was carried out in the context of Indonesia's PKH program, a conditional cash transfer that entitles households to about $\$ 150$ per year for up to six years and found the same result. However, there is evidence for elite capture in certain programs in Indonesia (Alatas et al. 2013a) — in particular, we find that the relatives of elites are up to $8 \%$ more likely to receive certain government programs. But since these relatives of the elites are not much richer than the rest of the population, the distortion created by this bias turns out to be small-eliminating elite capture entirely would improve the welfare gains from these programs by less than one percent. Our calculations suggest that this improvement is hugely dominated by what could be achieved by improving PMT data to be used in identifying the poor.

\footnotetext{
${ }^{7}$ This $50 \%$ error rate is clearly somewhat overstated since it includes some cases where our measure of consumption is wrong and therefore the PMT outcome appears to be wrong even though its is actually correct.
} 
That said, the experience from Indonesia may not be entirely general; Atanassova et al. (2013) find evidence of more elite capture in the TPDS program in India which has community targeting. As mentioned above, the TPDS program also suffers a lot from both inclusion and exclusion errors. With or without elite capture, the experience of community targeting seems to leave much scope for improvement.

The other option is self-targeting. The idea is to require the beneficiary to take some costly action to qualify to get the program, which would then screen out those who don't really need the program. The costly action can be as simple as getting some perinatal check ups to qualify for a subsidy towards a hospital birth (as in India's JSY) but it could be a requirement of working 8 hours to get paid for that day (as in India's Mahatma Gandhi National Rural Employment Program (MNREGA)), which is obviously much more onerous. Self-targeting, when well designed, has the potential to identify the right people without any data collection; indeed because people self-select based on their true need (rather than the part of the need that shows up in what we can measure) it can do much better than any data-based protocol in addressing true need. The disadvantage, of course, is that the cost imposed on the beneficiaries is a real social cost that has to be traded off against the potential benefit of better targeting. It is also obviously important to get the cost right so that it discriminates between the right people.

In Alatas et al. (2013b) we use an RCT to test the effectiveness of self-targeting in the context of Indonesia's PKH program. A mechanism that requires potential beneficiaries to apply and make a declaration before they get (proxy) means tested was compared against the status quo, which is automatic selection based on some previous PMT. The results demonstrate quite clearly that the first, hybrid mechanism, does generate significant amount of self-selection based on both observables and un-observables. The resulting selection of beneficiaries is much poorer than under the status quo and both inclusion and exclusion errors are reduced. On the other hand, making the application process more painful (beyond the few hours that it took in the baseline treatment) made things worse. It appears that a small cost is enough to discourage those who have a low probability of being selected after the eventual PMT and any further cost just depresses application rates across the board without improving selection.

A pure workfare program like MNREGA works very differently from this kind of one-time application cost. First, it can be much more flexible; those who opt not to do the PKH application at some point of time, or just get left out by mistake, are excluded until the application process gets reopened, potentially only in six years. By contrast MREGA jobs are, in principle, available on demand, so someone who loses his job today is supposed to be able to show up for MNREGA work tomorrow.

In practice MNREGA works much less seamlessly. Jobs are often not available on demand (Murgai et al. 2013). In part, this is the result of an effort to make MNREGA useful, which means projects under MNREGA need to be planned, proposed and reviewed ahead of time. This means both that the number of jobs being offered is more or less fixed at a point of time, and that the number of jobs available depends on the willingness of the village government to propose and implement projects, which often turns out to be a binding constraint. To make matters worse, program rules designed to improve accountability - which is important, given the enormous leakages that have been documented (Niehaus \& Sukhtankar 2013)—often slow down fund 
flows

Another important aspect of MNREGA is the effect on net labor supply to the rest of the economy. It turns out that this effect is substantial enough to raise market wages of the unskilled by $4.5 \%$ (and by $9 \%$ in the states where program was effectively implemented) as Imbert and Papp (2012) have shown for MNREGA. ${ }^{8}$ This tells us that the benefits of a program like MNREGA can spill over to large numbers of non-participants.

Whether this is good news or bad news is, however, not entirely obvious; it depends, first, on what is happening to labor supply. Since the MNREGA work is mostly in the dry season, it is possible that the entire effect is just more work for those who were previously constrained by lack of work. But it is also possible that some work is lost to the market i.e. a pure substitution effect. If the work that is being displaced by the rise in wages is more socially productive than the use the government is making of the MNREGA labor, there could be some welfare loss. On the other hand, not all the reduction in labor supply to the market may be job switching - in part it could be an income effect on the demand for leisure; this is conventionally viewed as efficiency neutral.

There is also the issue of targeting. These spillover effects obviously limit the targeting benefits of MNREGA since many of these other beneficiaries have opted not to participate in workfare and may not be as poor as the program participants. However, though given that it is unskilled wages that go up, the extra benefits still mostly go to the poor.

Finally, there is the impact on nutrition; if the workfare program increases overall labor supply, as seems plausible, the demand for calories of those who are now working will also go up and, therefore, the effect on the nutrition of children, for example, may be limited. There is one tantalizing piece of evidence that suggests that this may be a real issue; one of the CCT programs that have the most negative effect on child anthropometric outcomes in the review article of CCTs by Manley et al. (2012) is the Rural Maintenance Program in Bangladesh, which is a workfare program.

In sum, targeting transfers to the poor is not easy; each method of targeting comes with its own drawbacks. And the overall performance is often unacceptably poor: In the self-targeting version of the PKH program only $61 \%$ of the bottom $5 \%$ (who would have probably all qualified) applied, and only $16 \%$ eventually got the benefits; under the method currently used by the government the fraction of the bottom $5 \%$ who got the program was even lower, just $7 \%$. This is for a program that intended exactly for this group.

\section{Concluding thoughts}

The design of the best transfer programs for promoting better nutrition turns out to be more complex than one might have imagined; in particular, while there are lots of examples and some good evidence, there remain many uncertainties about what works best. However, there is also a lot that we have learnt and they help in sharpening the next set of questions.

\footnotetext{
${ }^{8}$ Muralidharan et al. (2014) find a similar result.
} 
Given the evidence, periodic cash transfers (rather than food) seem to be the appropriate candidate for further experimentation. In terms of identifying beneficiaries, self-targeting seems to be the obvious area to explore further.

Within self-targeting, the obvious idea to explore, I feel, is a universal monthly or weekly cash transfer that can only be picked up by the designated beneficiary by putting in her biometric information at certain specific locations. These locations need to be designed so that each person has several possible alternatives that she can go to (to prevent hold-ups) but there is some wait and probably a small travel cost involved in picking up the cash (so not too many locations). If someone does not show up to pick up their entitlement for the month/week, the money reverts back to the government.

This scheme has the advantage of eliminating all external targeting; the only targeting comes from self-selection generated by the (small) cost of going to pick up the money. I believe that even a small cost would discourage a lot of people who do not need the money, especially since the cost only gets you the (relatively) small amount of money that you are supposed to get for that month. On the other hand, if anyone falls into hard times, they can always go and claim their current month's amount-since there is no verification stage, no PMT as in the PKH selftargeting protocol which gives this scheme the flexibility that MNREGA was meant to havebut does not.

Relative to a one-time sign up cost, the fact that one has to go every month to pick up the money adds some cost (but really nothing compared to a true workfare program) but makes it more likely that the rich will select out even without the verification stage. Dropping the verification stage, on the other hand, limits the scope for both errors and corruption, both of which are serious concerns.

Of course, all of this awaits a proper experimental evaluation. It may turn that the small cost does not generate enough self-selection. It could also generate the wrong kind of self-selection; perhaps many of the poor will assume that the procedure is more complicated than it actually is and opt to stay away. Marketing the intervention so that everyone actually believes that it is universal and open to anyone is obviously important, and more generally we will need to be mindful of the failure of most anti-poverty programs to reach the poorest.

One other important outcome of any evaluation will be effect on wages, since a big part of the impact of MNREGA, for example, came from that. If the source of that effect is substitution, we would not expect to see a similar effect from an unconditional cash transfer; of course, that needs to be traded off against the fact that there would be no distortionary effect on output. By contrast, if the wage effect is the result of an income effect on leisure, then the unconditional cash transfer should have a similar effect (but of course in this case there is no distortionary effect on output).

To end, a word of caution; a universal cash transfer is conceptually simple but that does not mean that there are no logistics to be figured out. To take a mundane example, it is not obvious whether the target of the transfer should be a household or an individual (say an adult). Individual level transfers are simpler but more wasteful (more trips would have to be made, for example). On the other hand, a household level transfer requires defining households and 
keeping track of them over time.

\section{Bibliography:}

Alatas, Vivi, Abhijit Banerjee, Rema Hanna, Benjamin A. Olken, Ririn Purnamasari, and Matthew Wai-Poi, "Does Elite Capture Matter? Local Elites and Targeted Welfare Programs in Indonesia," NBER Working Paper No. 18798, February 2013 a.

http://www.nber.org/papers/w18798

Alatas, Vivi, Abhijit Banerjee, Rema Hanna, Benjamin A. Olken, Ririn Purnamasari, and Matthew Wai-Poi, "Ordeal Mechanisms In Targeting: Theory And Evidence From A Field Experiment In Indonesia," NBER Working Paper No. 19127, June $2013 \mathrm{~b}$.

http://www.nber.org/papers/w19127

Alatas, Vivi, Abhijit Banerjee, Rema Hanna, Benjamin A. Olken, and Julia Tobias. "Targeting the Poor: Evidence from a Field Experiment in Indonesia." American Economic Review, 102(4): 1206-40, 2012.

Atanassova, Antonia, Paul Niehaus, Marianne Bertrand, and Sendhil Mullainathan, "Targeting with Agents," American Economic Journal: Economic Policy, 5(1): 206-38. 2013. https://www.aeaweb.org/articles.php?doi=10.1257/pol.5.1.206

Bandiera, Oriana, Robin Burgess, Narayan Das, Selim Gulesci, Imran Rasul, Munshi Sulaiman, "Can basic entrepreneurship transform the economic lives of the poor?", Economic Organisation and Public Policy Discussion Papers, EOPP 043. The London School of Economics and Political Science, Suntory and Toyota International Centres for Economics and Related Disciplines, London, 2013.

Banerjee, Abhijit and Esther Duflo, "Economic Lives of the Poor," Journal of Economic Perspectives, 21(1): 141-167, Winter 2007.

Banerjee, Abhijit and Esther Duflo, Poor Economics: A Radical Rethinking of the Way to Fight Global Poverty, New York: Public Affairs, 2011.

Banerjee, Abhijit, Esther Duflo, Nathanael Goldberg, Dean Karlan, Robert Osei, William Parienté, Jeremy Shapiro, Bram Thuysbaert, and Christopher Udry, "A multifaceted program causes lasting progress for the very poor: Evidence from six countries," Science Magazine, Vol. 348, No. 6236, May 2015. http://www.sciencemag.org/content/348/6236/1260799.full

Banerjee, Abhijit and Sendhil Mullainathan, "The Shape of Temptation: Implications for the Economic Lives of the Poor,” NBER Working Paper No. 15973, 2010.

http://economics.mit.edu/files/5575

Blattman, Christopher, Eric Green, Julian Jamison, and Jeannie Annan, “Women's entrepreneurship and intimate partner violence: A cluster randomized trial of microenterprise 
assistance and partner participation in post-conflict Uganda", Social Science \& Medicine (May): 177-188. 2015.

Blattman, Christopher, Nathan Fiala and Sebastian Martinez, "Generating Skilled SelfEmployment in Developing Countries: Experimental Evidence from Uganda," Quarterly Journal of Economics, (2014) 129 (2): 697-752. doi: 10.1093/qje/qjt057

Behrman, Jere and Anil Deolalikar, "Health and Nutrition" in Hollis Chenery \& T.N. Srinivasan (ed.), "Handbook of Development Economics," Amsterdam: Elsevier, edition 1, volume 1, number 1, January 1988.

Bryan, G., Chowdury, S., and Mobarak, A. M., "Under-investment in a Profitable Technology: The Case of Seasonal Migration in Bangladesh," Econometrica, Vol. 82, No. 5 (September, 2014), pp. 1671-1748. https://dl.dropboxusercontent.com/u/7911910/monga_ecta.pdf

Cunha, Jesse M., Giacomo De Giorgi, and Seema Jayachandran, "The Price Effects of Cash Versus In-Kind Transfers.” NBER Working Paper No. 17456, 2011.

Deaton, Angus and J. Dreze. "Nutrition in India: Facts and interpretations," Economic and Political Weekly, 44(7):42-65, February 2009.

Deaton, Angus and Shankar Subramanian, "The Demand for Food and Calories," The Journal of Political Economy, Volume 104, Issue 1 (Feb., 1996), pp. 133-162. http://salome.lse.ac.uk/courses/ec307/L/subramaniandeaton.pdf

Duflo, Esther, "Grandmothers and Granddaughters: Old Age Pension and Intra-household Allocation in South Africa," World Bank Economic Review 17(1): 1-25, 2003. http://economics.mit.edu/files/732

Field, Erica, and Rachel Glennerster, "Empowering Girls in Rural Bangladesh," mimeo, Poverty Action Lab 2013. http://www.povertyactionlab.org/evaluation/empowering-girls-ruralbangladesh

Fiszbein, Ariel and Norbert Schady, "The Impact of CCTs on Consumption Poverty and Employment," in Fiszbein, Ariel; Schady, Norbert; Ferreira, Francisco H.G.; Grosh, Margaret; Keleher, Niall; Olinto, Pedro; Skoufias, Emmanuel (eds.), Conditional Cash Transfers: Reducing Present and Future Poverty. Washington, DC: World Bank, 2009, pp. 103-126. http://siteresources.worldbank.org/INTCCT/Resources/5757608-1234228266004/103-126_PRRCCT ch04.pdf

Haushofer, J. and Jeremy Shapiro, "Household Response to Income Changes: Evidence from an Unconditional Cash Transfer Program in Kenya," November 2013. http://www.princeton.edu/ joha/publications/Haushofer_Shapiro_UCT_2013.pdf

Hoddinott, John, Daniel Gilligan, Melissa Hidrobo, Amy Margolies, Amber Peterman, Shalini Roy, Susanna Sandström, Benjamin Schwab, and Joanna Upton, "Enhancing WFP's Capacity and Experience to Design, Implement, Monitor and Evaluate Vouchers and Cash Transfer 
Programmes," International Food Policy Research Institute, May 2013. http://documents.wfp.org/stellent/groups/public/documents/resources/wfp257513.pdf

Imbert, Clement and John Papp, “Equilibrium Distributional Impacts of Government Employment Programs: Evidence from India's Employment Guarantee,” PSE Working Papers n²012-14, 2012.

Levy, Santiago, "Good Intentions, Bad Outcomes: Social Policy, Informality, and Economic Growth in Mexico,” Washington, D.C.: Brookings Institution Press, 2008.

Manley, J., Gitter S., Slavchevska V., "How Effective are Cash Transfer Programmes at Improving Nutritional Status?" London: EPPI-Centre, Social Science Research Unit, Institute of Education, University of London July 2012.

http://r4d.dfid.gov.uk/PDF/Outputs/SystematicReviews/Q33-Cash-transfers-2012Manley-rae.pdf

Muralidharan, Karthik, Paul Niehaus and Sandip Sukhtankar, "Building State Capacity: Evidence from Biometric Smartcards in India", NBER Working Paper 19999, 2014 (updated)

Murgai, Rinku, Martin Ravallion and Dominique van de Walle, "Is Workfare Cost-Effective against Poverty in a Poor Labor-Surplus Economy?," World Bank Policy Research Working Paper 6673, October 2013.

Niehaus Paul, and Sandip Sukhtankar, "The marginal rate of corruption in public programs: Evidence from India,” Journal of Public Economics Volume 104, pp. 52-64, August 2013. http://www.sciencedirect.com/science/article/pii/S0047272713001084

Ravallion, Martin, "How Relevant is Targeting to the Success of an Antipoverty Program?" World Bank Research Observer, (2009) 24 (2): 205-231. doi: 10.1093/wbro/lkp009

Schady, Norbert and José Rosero, “Are Cash Transfers Made to Women Spent Like Other Sources of Income?," World Bank Policy Research Working Paper 4282, Impact Evaluation Series No. 17. Washington, DC: The World Bank, 2007.

Schady, Norbert and José Rosero, “Are Cash Transfers Made to Women Spent Like Other Sources of Income?," Economics Letters 101 (3): 246-48, 2008.

Skoufias, Emmanuel, Mishel Unar, and Teresa Gonzalez-Cossio, "The impacts of cash and inkind transfers on consumption and labor supply: experimental evidence from rural Mexico," Impact Evaluation series; no. IE 27 Policy Research working paper; no. WPS 4778. Washington, DC: World Bank, 2008. http://documents.worldbank.org/curated/en/2008/11/10087907/impactscash-in-kind-transfers-consumption-labor-supply-experimental-evidence-rural-mexico

Strauss, John and Duncan Thomas, "Human Resources: Empirical Modeling of Household and Family Decisions," in: Behrman, J.R., Srinivasan T.N. (Eds.), Handbook of Development Economics, pp. 1183-23. Vol. IIIA, Chap. 34, NorthHolland Pub. Co., Amsterdam, 1995. 